\title{
On the Research of Global History and Cultural Interaction in East Asia
}

\author{
LI Xuetao*, SHEN Guowei**
}

\section{I}

Compared with previous research that has been conducted on world history, which separately focuses on each geographical region and history as it relates to different fields, the research concepts of global history break the spell of "nation", the concept which is characteristic of modern times. Its research field is humanity as a whole that is made up of different regions, nationalities, religions, cultures and languages. The disciplinary division between East Asia's history and the world's history vanishes accordingly, and they are all integrated into the global history for the overall research.

Since the era of great sea voyages, Europe has been accustomed to exporting its interests to every corner of the world by spreading its national or religious ideologies, a trend which is one of the features of modernity and, in a real sense, has contributed to the formation of world trade. The formation of the global trading system has given rise to the reallocation of global resources and the spread of European technology throughout the world. The grand voyage of the aliens stimulates the formation of a national consciousness, and the relationship between sovereign states has been defined in the form of various treaties. From the perspective of the colonial expansion with Europe as the center, the world is merely a collection of places within the reach of Europe. As a discipline, the establishment of global history breaks up the monopoly of the viewpoints of Euro-centrism with the development of cross-cultural interaction. The previous practice which takes the historical experience of Europe as the criteria for measuring other societies' development has been abandoned by today's academic circle. William McNeill

* Prof. Li Xuetao 李雪涛 is dean of School of History at Beijing Foreign Studies University.

** Prof. Shen Guowei 沈国威 is director of Institute of Oriental and Occidental Studies at Kansai University. 
(1917-2016), the father of global history, claims, "Historical change was largely provoked by encounters with strangers." 1 In particular, the contact and communication with heterogeneous cultures occasionally give rise to the adjustment and change of numerous established conventions. To a large extent, historical transformation is triggered by the encounters of one culture with a foreign culture, and it is this drive that fomented the formation and development of Eurasian "ecumene". Marshall Hodgson (1922-1968) even believes, "The evolution of Western Europe depended on the course of development of Afro-Eurasian historical life as a whole."2

The concepts of global history transcend the ways people have viewed the world and space in the past. Although the birth of modernity began in the West, it came into being as a result of the collision between the West and other heterogeneous civilizations. Michael Geyer (1947-), a German professor of European history at The University of Chicago, and Charles Bright, another historian at The University of Chicago, even state that non-Western countries (including China), as a kind of counter-force, are the sources of the strength for generating global integration, helping the world merge gradually in the process of integration and connecting the regional histories with world history as a whole. ${ }^{3}$

Global history, as a kind of methodology and a field of research, is actually a superordinate concept and a broad academic domain waiting to be explored, and no one one has the means to exhaust the potential knowledge contained therein. At present, we are now integrating the research results in every domain of global history and East Asia from the perspective of academic history, in the hope of discovering some new research results on global history and East Asia. The topic, Research of Global History and Cultural Interaction in East Asia, is a major that is not only only confined to a certain person in a certain discipline, but is inevitably the outcome of positive participation and close interaction of scholars in different majors and disciplines, and only after the concerted efforts of several generations can we hope to achieve preliminary results.

\section{II}

East Asian Cultural Interaction Studies is an important academic concept which was proposed by a research team of Kansai University, Japan. The

1 William McNeill, "The Changing Shape of World History," History and Theory, Vol. 34, No. 2 (May, 1995), pp. 8-26, see p. 15 here.

2 Marshall Hodgson, "The Interrelations of Societies in History," Comparative Studies in Society and History, Vol. 5, No. 2 (Jan., 1963), pp. 227-250, see p. 250 here.

3 Michael Geyer \& Charles Bright, "World History in a Global Age," The American Historical Review, Vol. 100, No. 4 (Oct., 1995), pp. 1034-1060. 
reason why "interaction" is used rather than "communication" is that the team defines the characteristics of its research as cross-border, interactive, mutual views between the peripheral area and the central area. In June 2007, the Ministries of Education, Culture, Sports, Science and Technology of Japan approved the plan of the Institute for Cultural Interaction Studies (ICIS) for which the scholars of history, intellectual history, and East-West language contact in Kansai University had jointly applied. In October of the same year, Professor Yu Ying-shih (1930-) presented an in-depth exposition on the civilization theory of Arnold Joseph Toynbee (1889-1975) and Huntington Samuel (1927-2008) in a keynote speech delivered at the preliminary convention of the Society for Cultural Interaction in East Asia. In his speech, he stated the significance of establishing the Cultural Interaction Studies and setting up this international society for promoting related research. In June 2009, the Society for Cultural Interaction in East Asia was formally set up in Osaka, Japan. The tenet of the Society is to have a dynamic command of the formation, interaction, conflict, transition, and integration etc. between the cultures in East Asia, conducting the cultural interaction by synthesizing a variety of methodologies of the humanities, namely the multi-directional interpretation with mutual interference. They hope through this process to improve academic exchanges among scholars from East Asian countries.

While conducting academic research, the scholars on the team advocate that they should strive to carry out their research with global vision and creativity. Although the Society has set their research object as "cultural interaction in East Asia", "the cultural interaction between the East and the West in East Asia" and "the cultural interaction between various regions of East Asia" are also included in the topic of research. While analyzing the actual characteristics of cultural interaction, the team will transcend and break through the so-called "one-to-one "research limitations between two countries or two regions, and strive to flexibly use the "many-to-many" research approach among many countries and regions. The geographical division based on nations, civilizations or terrestrial space cannot be the research boundary of scholars nowadays. ${ }^{4}$

\section{III}

For the view of global history and East Asian Cultural Interaction Studies, the cultural resource of East Asia in itself can also provide some unique perspectives and theoretical support. "Tao" (“道” in Chinese, meaning prin-

4 See the subtitle of The Birth of the Modern World by Sir Christopher Bayly (19452015)-"global connections and comparisons". Christopher Bayly, The Birth of the Modern world 1780-1914: Global Connections and Comparisons, Oxford 2004. 
ciple or logos) and "Utensil” (“器” in Chinese, meaning tool or utensil) are a pair of significant categories in the history of Chinese philosophy. Just as The Great Treatise I of The Book of Changes states, "The metaphysical is called Tao, and the physical is called Utensil." It can be concluded that the "Tao" refers to intangible principles, while "Utensil" refers to the tangible tools. During the Northern Song Dynasty, philosophers conducted in-depth discussions on the relationship between the "Tao" and "Utensil". Zhu Xi, who followed the viewpoint of Cheng Yi (1033-1107) and Cheng Hao (10321085), two famous philosophers during the Song Dynasty, conceived that "Everything which has forms and appearances are Qi (“气” in Chinese, meaning substance or existence), and those which are the principles of Utensil are Tao." (Book to Lu Zijing) Here he emphasizes that "Tao" and "Utensil" are not separate concepts, and there is no difference between them. ${ }^{5}$ On the other hand, Lu Jiuyuan (1139-1193), another philosopher during the Southern Song Dynasty, disagreed with Zhu Xi's viewpoint regarding the Tao and Utensil, and argued that the Tao is fundamental while the Utensil is nonessential, and purposed that the Tao comes before the Utensil. ${ }^{6}$

During the Ming and Qing Dynasties, as Western Learning was being introduced into China along with Christianity, most traditional intellectuals believed that the so-called Western Learning was just the "art of being a common man" at the "Utensil" level, rejected the "Tao" of Western Learning, and accepted the scientific knowledge of modern times conditionally. What Xu Gunagqi (1562-1633) learned from Matteo Ricci (1552-1610) was no more than astronomy and calendrical calculations of Western Learning introduced by the missionaries, which were indeed lost in the traditional Chinese Learning. Around the middle of the 19th century, Zheng Guanying (18421921), a famous enlightenment thinker, advocated that the "Tao is fundamental while Utensil is non-essential", in which "Tao" refers to the tradi-

5 "Utensil is Tao, while Tao is Utensil. Tao isn't separated from Utensil, and Tao is just the principle of Utensil. For example, a chair is a Utensil. Being seated is the principle of this chair. The human body is a Utensil, and the language and the action are the principles of the human body. Principle is only above Utensil, and the principle and Utensil are not separated from each other." Li Jingde, Zhuzi yulei (Classified Conversations of Zhu Xi), Beijing: Zhonghua Shuju, 1986, Vol.77, p. 1970.

6 "The acquisition of morality is primary, the comprehension of skill is secondary, the acquisition of morality is put first, and the fulfillment is put after [...] Archery, chariot-riding, calligraphy and mathematics etc. are skills, which are humble, base, inferior and insignificant." Lu Jiuyuan (1139-1193), "Yu Tao Zanzhong" (Letter to Tao Zanzhong), in Xiangshan xiansheng quanji (The Complete Works of Xiangshan), Sibu Congkan chubian, Jing Shanghai hanfenlou Ming edition, Vol.1161, juan 15, p. 2a-b. 
tional Confucian ethical principles, and "Utensil" refers to the western science and technology. However, the Confucian ethical principles, the lifeblood of Chinese culture and the basis for maintaining the foundation of China's political structure and ruling order, cannot be impacted or even replaced by Western Learning. Any attempt to enter the level of "Tao" through "Utensil" is bound to meet firm opposition from the court officials. If "Tao is fundamental while Utensil is non-essential" is still a philosophical point of view, then the later "Chinese-style westernization" is the real practical proposition, which has become the general policy guiding the New Deal for decades by the Westernizationers. Arnold Joseph Toynbee (1889-1975), a British historian, penned in his analysis of "psychology of clash" when the Far East was shocked by the West:

"...the reception of a foreign culture is a painful as well as a hazardous undertaking; and the victim's instinctive repugnance to innovations that threaten to upset his traditional way of life makes the experience all the worse for him..."7

Since the late Ming Dynasty, the Chinese court officials deeply believed that Western Learning embodied "an omen of subverting their traditional lifestyle" and thus resisted it instinctively. Even until the late Qing Dynasty, Zeng Guofan (1811-1872), who was head of the distinctive officials in the Tung-Chih Restoration, still believed, "The merit of the West is nothing more than the ingenious manufacturing, powerful ships and cannons. Since the barbarians do not know any etiquette, they could not provide convincing speeches on politics. Even though there is politics for them, it does nothing but refer to defying their superiors, and start rebellions, expels and murders the monarch, scorns the cardinal guides and the constant virtues, and goes against ethics. Do they deserve to be followed?"8 According to Neo-Confucianism, everything in Confucian tradition has been elevated to the level of "Tao", while Western Learning is only worth our learning at the level of "Utensil". This is much like the so-called "inlaying" craftsmanship: if something is embedded in the gap of another system and is integrated to be a whole, it could achieve more practical performance in the new system. During the Ming and Qing Dynasties, Western Learning only played a role of "inlaying" as an "object". It is easier to understand the relationship between Chinese Learning and the so-called "Western Learning" during the Ming and Qing Dynasties using the theory of Tao and Utensil.

7 Arnold Joseph Toynbee, The World and the West, (NY and London: Oxford University Press, 1953), pp. 81-82.

8 Quoted from Xuan Fan's "Zhengzhi zhi yinguo guanxi lun" (On the Relationship Between Cause and Effect in Politics), in: Dongfang Zazhi (Eastern Miscellany), 1910, Vol.7, No.12, p. 283. 
As for the subsequent conditions, we hope to borrow the "harmony" notion of the Huayan Sect for proper explanation. Harmony means completeness and integration without obstacle. That is, all subjects can maintain their original stance complete and intact as a whole, and can interact and integrate with each other without contradiction or conflict. The ideal state of two subjects interacting and integrating is expressed here. Fernand Braudel (1902-1985), a French historian, claims that although the cultural belts based on geographical environments are relatively stable, they also propagate and permeate mutually, and there is no cultural boundary which is unchangeable and completely closed. ${ }^{9}$ William McNeill adds that the ultimate spring of human variability, of course, lies in our capacity to invent new ideas, practices and institutions. But invention flourishes best when contact with strangers compels different ways of thinking and doing to compete for attention. ${ }^{10}$ Therefore, it is the interaction between cultures that promotes progress of human society.

In the late Qing Dynasty, Western Learning, merely as a means of "inlaying", played a decorative role in Confucianism at the level of Utensil, which obviously could not meet the needs of the society. In his first essay, Yan Fu regarded "western techniques" such as the steam turbine and military machinery, etc. as "the rough skills at a physical level."11 However, in his essay On Our Salvation which he wrote two months later, he borrowed Chuang-tzu's viewpoint that the "Tao is omnipresent and revealed in the humble objects of life" to express Francis Bacon's (1561-1626) ${ }^{12}$ scientific view of nature. Later, Yan Fu tirelessly added the propositions on principles and methods of metaphysics provided by physics in his translations and discussions, including Evolution and Ethics. ${ }^{13}$ However, Chinese traditional intellectuals such as Tang Zhen (1856-1917), believe that the westerners' "Utensil" must have some kind of Tao value behind its instrumental characteristics, he says, "Perhaps what China held on to was the Tao of metaphysics, while what the west specialized in was the Utensil of physics. China cherished its Tao headstrongly and gradually lost its so-called Utensil, while the West strived to work on the Utensil while sometimes secretly catering the

9 Fernand Braudel, translated by Xiao Chang etc., Wenming shigang (Grammaire des Civilisations), Nanning: Guangxi Normal University Press, 2003, p. 30-32.

10 William McNeill, "The Changing Shape of World History," History and Theory, Vol. 34, No.2, (May 1995), p.15.

11 Yan Fu, "Lun shibian zhi ji" (On the Urgent Change of the World), edited by Wang Shi, Yan Fu Ji 1 (The Collection of Yan Fu I), Beijing: Zhonghua Shuju, January 1986, p. 2.

12 Yan Fu, "Jiuwang juelun" (On Our Salvation), edited by Wang Shi, Yan Fu Ji 1 (The Collection of Yan Fu I), Beijing: Zhonghua Shuju, January 1986, p. 46.

13 Shen Guowei, Yan Fu yu kexue (Yan Fu and Science), Nanjing: Phoenix Publishing House, May 2017. 
Tao. The West adhered to and pursued it, transformed and comprehended it, truly understood it, and invented objects that were derived from China. Why could not China invent objects that were derived from the West?"14 After that, "harmony", as the interaction and integration between the subjects in different cultures, gradually replaced "inlaying" to become the new paradigm of cultural interaction, ${ }^{15}$

\section{IV}

Therefore, the holistic study of the humanities has become a trend in this globalized world. The "Global Turn" of history as seen in the backdrop of a modern globalized world, is a global view of history and accepting global history as a research object: the former is a kind of new perspective and new method of historical research and historical writing, i.e. compiling macroscopic world history, investigating microscopic historical cases with the views of integration and relation, or understanding cross-country historical phenomena with a transnational vision; while the latter is a research domain and a branch of history studies, i.e. the study of history transcending nations. Global history and East Asian Cultural Interaction Studies aims at eliminating the boundary between nationality and country, placing the research object in a broad and correlative context so as to understand and explore from an comprehensive viewpoint, and breaking through the various kinds of previous centrist prejudice of human cognition. The 9th International Symposium of Society for Cultural Interaction in East Asia was held in Beijing Foreign Studies University, during which the latest achievements assuming the above context as the research standpoint and methods in the fields of global history and cultural interaction in East Asia were demonstrated. Basically, what global history and cultural interaction emphasize is global interaction. The theme of this annual conference was "View of Global History and Knowledge Transfer in East Asia". The contents of the symposium include

14 "Zhiyan-Zhongxue diliu" (Warnings-Secondary Education No. 6), in: Xiaoshan wenshi ziliao xuanji 4 - Tang Shouqian shiliao zhuanji (Selected works of the County Xiaoshan Literary and Historical Materials. Vol. Four- The Monograph of Historical Material by Tang Shouqian), 1993, Xiaoshan: Zhechu Shulin (90), No. 59 , p. 225.

15 On the conceptual applications of "inlaying (xianqian 镶嵌)" and "harmony (yuanrong 圆融)", appreciation is given to Professor Kun-Chiang Chang, in the Department of East Asian Studies, Taiwan Normal University, who delivered a speech - “Wushidao de 'fenliu 分流” yu 'shentou 渗透” xin quanshi” (The New Interpretation of Bushido's "Distributary" and "Infiltration") at "the 8th International Symposium of Society for Cultural Interaction in East Asia", which was included in The Conference Proceedings on the 8th Annual Symposium of Society for Cultural Interaction in East Asia, Osaka: Kansai University, May 2016, pp.665-671. 
the investigation into the interactions formed in the domains of politics, economy and culture etc. between East Asia and other people groups with different regions, nationalities, cultures since the Age of Sail. Besides the research on the generally \& regionally global history and cultural interaction in East Asia, the monographic research between the world and the cultures in East Asia is also included, such as the history of trade, immigration, missionaries, linguistic communication, knowledge transfer, science and technology, disease, concepts, translation and overseas study etc. These subjects are included because they are related with the "problem-oriented history" advocated by the Annales School in France. The Annales School stressed the significance of "analysis" and "questioning" in historical research.

Liu Xincheng (1952- ) listed the eight forms of interactive modes expressed by western scholars on global history: 1. Elaborate the mutuality and bidirectionality of cultural influence when different groups of people "encounter" each other; 2. Describe every sort of "communicative network" or "symbiosis circle" ever existing in human history; 3. Expound how the inventions of one region give rise to the chain reactions in the world; 4 . Discuss the relationship between "small places" and the "big world"; 5. "The globalization of local history"; 6. The thematic comparative studies on a global scale; 7. The research on ecological history and environmental history; 8. Evaluate the laws of interaction and destiny. ${ }^{16}$ The above-listed themes of Global History and East Asia could all be summed up in the interactive modes listed by LIU Xincheng. The American historian Jerry Bentley (19492012) claimed that world history (global history) investigated "historical processes that have not respected national, political, geographical, or cultural boundary lines, but rather have influenced affairs on transregional, continental, hemispheric, and global scales. These processes include climatic changes, biological diffusions, the spread of infectious and contagious diseases, mass migrations, transfers of technology, campaigns of imperial expansion, cross-cultural trade, the spread of ideas and ideals, and the expansion of religious faiths and cultural traditions." 17 The history of cultural development in East Asia not only has its own distinctive tradition, it also is history with incessant innovations and breakthroughs resulting from contact and interaction within East Asia and between East Asia and the rest of the world. It is in the light of the research on global history and cultural interaction in East Asia that we see that the present civilization of East Asia origi-

16 Liu Xincheng, "Zai hudong zhong goujian shijie lishi” (Building the World History in Interaction), in: Guangming Ribao (Guangming Daily), February 17, 2009.

17 Jerry H. Bentley, "The New World History," in Lloyd Kramer and Sarah Maza, eds., A Companion to Western Historical Thought (Oxford: Blackwell, 2002), pp.393-416, see p. 393 here. 
nated from divergent cultural contact and thus displays the global meaning of East Asian culture.

Global history and cultural interaction focus on the cultural exchanges between Europe and East Asia since the Age of Sail. The historical, ideological, religious and cultural contents of ancient East Asia are discussed, which are the re-elucidation and reconstruction under the impact of Western Learning. After getting rid of its original context and strands, the ideology of East Asia takes on the unexpected, fresh interpretation and a meaning in the new context. Every kind of ideology has the social and academic soil in which they grow and develop, and the change of soil would apparently result in the difference between citrus and trifoliate orange. Any awareness of the problems is a re-reflection based on the stimulation from the era and environment. Strange thoughts and concepts become activated in the new context once integrated into the strand and context of local culture, and thus play a pivotal role. As for the research conducted on East Asia, scholars in exotic countries have brought the culture of East Asia into their context, signifying that the culture of East Asia has transcended its original historical space and time, and achieved the extra value. 